\title{
Origins of multisynaptic projections from the basal ganglia to the forelimb region of the ventral premotor cortex in macaque monkeys
}

\section{$\operatorname{AUTHOR(S):~}$}

Ishida, Hiroaki; Inoue, Ken-ichi; Takada, Masahiko; Hoshi, Eiji

\section{CITATION:}

Ishida, Hiroaki ... [et al]. Origins of multisynaptic projections from the basal ganglia to the forelimb region of the ventral premotor cortex in macaque monkeys. European Journal of Neuroscience 2016, 43(2): 258-269

\section{ISSUE DATE:}

2016-01

URL:

http://hdl.handle.net/2433/218581

\section{RIGHT:}

This is the peer reviewed version of the following article: IIshida, H., Inoue, K.-i., Takada, M., Hoshi, E. (2016), Origins of multisynaptic projections from the basal ganglia to the forelimb region of the ventral premotor cortex in macaque monkeys. European Journal of Neuroscience, 43: 258-269], which has been published in final form at https://doi.org/10.1111/ejn.13127. This article may be used for non-commercial purposes in accordance with Wiley Terms and Conditions for Self-Archiving.; この論文は出版社版でありません。引用の際には出版社版をご確認ご利用く ださい。; This is not the published version. Please cite only the published version. 
Research Reports/Neurosystem

Origins of multisynaptic projections from the basal ganglia to the forelimb region

of the ventral premotor cortex in macaque monkeys

$\mathrm{BG}$ projections to the forelimb region of $\mathrm{PMv}$

Hiroaki Ishida $^{1^{*}}$, Ken-ichi Inoue ${ }^{2 *}$, Masahiko Takada $^{2}$, Eiji Hoshi $^{1}$

${ }^{1}$ Frontal Lobe Function Project, Tokyo Metropolitan Institute of Medical Science, Setagaya-ku, Tokyo, Japan

${ }^{2}$ Systems Neuroscience Section, Primate Research Institute, Kyoto University, Inuyama, Aichi, Japan

*These authors contributed equally to this work.

\section{Co-corresponding Authors:}

Dr. Masahiko Takada

Systems Neuroscience Section, Primate Research Institute, Kyoto University, 41-2

Kanrin, Inuyama, Aichi 484-8506, Japan

e-mail: takada.masahiko.7x@kyoto-u.ac.jp

\section{Dr. Eiji Hoshi}

Frontal Lobe Function Project, Tokyo Metropolitan Institute of Medical Science, 2-1-6

Kamikitazawa, Setagaya-ku, Tokyo 156-8506, Japan

e-mail: hoshi-ej@igakuken.or.jp 
Manuscript contains 10 figures, 1 table and 40 pages.

Number of words: Manuscript, 9615; Abstract, 250; Introduction, 523.

Keywords: rabies virus, globus pallidus, striatum, subthalamic nucleus, substantia nigra 


\section{Abstract}

The ventral premotor cortex (PMv), occupying the ventral aspect of area 6 in the

frontal lobe, has been implicated in action planning and execution based on visual

signals. Although the PMv has been characterized by cortico-cortical connections with

specific subregions of the parietal and prefrontal cortical areas, a topographical

input/output organization between the PMv and the basal ganglia (BG) still remains

elusive. In the present study, we employed retrograde transneuronal labeling with rabies

virus to identify the origins of multisynaptic projections from the BG to the PMv. We

injected the virus into the forelimb region of the PMv, identified in the ventral aspect of

the genu of the arcuate sulcus, in macaque monkeys. The survival time after the virus

injection was set to allow either the second- or third-order neuron labeling across two or

three synapses. The second-order neurons were observed in the ventral portion (primary

motor territory) and the caudodorsal portion (higher-order motor territory) of the

internal segment of the globus pallidus. Subsequently, the third-order neurons were

distributed in the putamen caudal to the anterior commissure, including both the

primary and the higher-order motor territories, and in the ventral striatum (limbic

territory). In addition, they were found in the dorsolateral portion (motor territory) and 
ventromedial portion (limbic territory) of the subthalamic nucleus and in the external segment of the globus pallidus including both the limbic and motor territories. These findings indicate that the PMv receives diverse signals from the primary motor, higher-order motor, and limbic territories of the BG. 


\section{Introduction}

The premotor (PM) cortex in primates, the rostral part of the frontal motor cortex

corresponding to Brodmann area 6 , plays a central role in the visual guidance of motor

behavior (Halsband \& Passingham, 1985; Wise, 1985; García-Cabezas \& Barbas, 2014;

Yamawaki et al., 2014; Barbas \& García-Cabezas, 2015). Seminal anatomical works of

the monkey brain have revealed that the PM is subdivided into two large sectors based

on the cytoarchitecture (Matelli et al., 1985, 1986; Barbas \& Pandya, 1987): one is a

dorsal region (PMd), lying dorsal to the spur of the arcuate sulcus, and another is a

ventral region $(\mathrm{PMv})$, lying ventral to the spur. Electrical stimulation and mapping

studies showed that there is a forelimb region in each of the PMd and PMv (Gentilucci

et al., 1988; Godschalk et al., 1995; Raos et al., 2003; Aflalo and Graziano, 1996;

Maranesi et al., 2012). Single cell recoding studies have revealed that the PMd and PMv

are involved in reaching and grasping movements in an area-specific manner (Kurata \&

Wise, 1988; Caminiti et al., 1991; Boussaoud \& Wise, 1993a, b; Kurata, 1993; Scott et

al., 1997; Kurata \& Hoshi, 2002; Raos et al., 2004, 2006; Umiltà et al., 2007; Yamagata

et al., 2009). By summarizing a large body of evidence, Hoshi and Tanji (2007) have 
proposed that the PMd plays a major role in action planning based on sensory-motor associations (indirect [conceptual] specification of action), whereas the PMv plays a major role in reaching and grasping a target object (direct guidance of limb movements).

Actually, the specific functional deficits that result from $\mathrm{PMd} / \mathrm{PMv}$ lesions endorse these notions (Rizzolatti et al., 1983; Kurata \& Hoffman, 1994; Kurata \& Hoshi, 1999;

Schieber, 2000; Fogassi et al., 2001).

The functional specializations between the PMd and the PMv may originate from distinct anatomical connectivity. Actually, these areas are interconnected with distinct subregions of the parietal and prefrontal cortical areas (Wise et al., 1997; Matelli et al., 1998; Rizzolatti et al., 1998; Luppino et al., 1999; Petrides \& Pandya, 1999). In addition to the connectivity within the cerebral cortex, it is most likely that neural networks linking these forelimb regions with the basal ganglia (BG) play functionally crucial roles, given that neurons in the BG code a variety of signals for planning and execution of reaching movement (Iansek \& Porter, 1980; DeLong et al., 1985) and their dysfunctions cause severe deficits in movement (Alexander \& Crutcher, 1990; Parent \& Hazrati, 1995a, b). 
In the present study we made an attempt to investigate the distributions of BG neurons giving rise to output projections to the forelimb region of the $\mathrm{PMv}$, as an extension of our previous anatomical study that has revealed the origins of multisynaptic projections from the BG to the corresponding region of the PMd (Saga et al., 2011). We employed retrograde transneuronal labeling with rabies virus (CVS-11) to identify the cellular origins of multisynaptic projections from the BG structures to the forelimb region of the PMv in macaque monkeys. We here show that the forelimb region of the PMv receives multisynaptic inputs from the primary motor territory, higher-order motor territory, and limbic territory of the BG.

\section{Materials and methods}

We used four male macaque monkeys (Macaca fuscata, weighing 5.4-6.9 kg;

provided by the Primate Research Institute, Kyoto University, Table 1). The experimental protocol was approved by the Animal Welfare and Animal Care

Committee of the Primate Research Institute, Kyoto University, and all experiments were conducted in accordance with the Guideline for the Care and Use of Animals of 
the Primate Research Institute, Kyoto University.

\section{Surgical procedures}

Monkeys were subjected to general anesthesia induced with ketamine hydrochloride (10 mg/kg, i.m.) and maintained with sodium pentobarbital (20 mg/kg, i.v.). During the surgical operation, monkeys were kept hydrated with lactated Ringer's solution (i.v.). An antibiotic (Rocephin; $75 \mathrm{mg} / \mathrm{kg}$, i.m.) and an analgesic (Buprenex; $0.01 \mathrm{mg} / \mathrm{kg}$, i.m.) were administered at the time of initial anesthesia. Each monkey's head was secured in a stereotaxic frame, and the skin and muscle were retracted to expose the skull over the right hemisphere. A craniotomy was made over the right frontal cortex, and the dura mater was cut to expose the superior and inferior limbs and the genu of the arcuate sulcus, which allowed us to visually inspect the tracer injection sites at the cortical surface. After confirming this, we proceeded with tracer injections.

\section{Viral injections}

The rabies virus (CVS-11 strain; $1.0 \times 10^{8}$ focus-forming units $/ \mathrm{ml}$ ) was derived from 
the Centers for Disease Control and Prevention (Atlanta, GA, USA) and donated by Dr.

S. Inoue (The National Institute of Infectious Diseases, Tokyo, Japan). For viral

injections, we used the same method as described in our previous reports (Hashimoto et al., 2010; Saga et al., 2011; Takahara et al., 2012). Two tracks of injections of rabies virus were made into the PMv of each of the four monkeys (Fig. 1, Table 1). The

injection sites were determined based on the results of our prior studies showing that the subdivision of the PMv located just ventral to the genu of arcuate sulcus plays a crucial role in reaching movement (Hoshi \& Tanji, 2002, 2006, 2007; Yamagata et al., 2009, Fig.1B, C). A viral suspension was slowly injected through a 10- $\mu$ l Hamilton microsyringe. Along each injection track, viral deposits were placed at two different depths: 3 and $2 \mathrm{~mm}$ below the cortical surface. At each depth, $0.5 \mu 1$ of the viral suspension was deposited. When injections were complete, the dura mater and bone flap were repositioned, and the scalp incision was closed.

\section{Histology}

After survival periods of 3-4 days after viral injection, monkeys were deeply 
anesthetized with an overdose of sodium pentobarbital $(50 \mathrm{mg} / \mathrm{kg}$, i.v. $)$ and

transcardially perfused with $10 \%$ formalin in $0.1 \mathrm{M}$ phosphate buffer ( $\mathrm{pH}$ 7.4). The

fixed brains were removed from the skull, postfixed in the same fresh fixative overnight

at $4^{\circ} \mathrm{C}$, and placed into $0.1 \mathrm{M}$ phosphate buffer ( $\mathrm{pH} 7.4$ ) containing $30 \%$ sucrose.

Coronal sections were then cut serially at $50 \mu \mathrm{m}$ thickness on a freezing microtome.

Every sixth section was processed for immunohistochemical staining for rabies virus by means of the standard avidin-biotin-peroxidase complex method. Following immersion in $1 \%$ skimmed milk, the sections were incubated overnight with rabbit anti-rabies virus antibody (donated by Dr. S. Inoue) in $0.1 \mathrm{M}$ phosphate-buffered saline (pH 7.4) containing $0.1 \%$ Triton $\mathrm{X}-100$ and $1 \%$ normal goat serum. The sections were then placed in the same fresh incubation medium containing biotinylated goat anti-rabbit IgG antibody (diluted at 1:200; Vector Laboratories, Burlingame, CA, USA), followed by the avidin-biotin-peroxidase complex kit (ABC Elite; Vector Laboratories). To visualize the antigen, the sections were reacted in $0.05 \mathrm{M}$ Tris- $\mathrm{HCl}$ buffer $(\mathrm{pH}$ 7.6) containing $0.04 \%$ diaminobenzidine, $0.04 \%$ nickel chloride, and $0.002 \%$ hydrogen peroxide. The sections were mounted onto gelatin-coated glass slides and then examined under the 
light microscope (Nikon Eclipse 80i, Tokyo, Japan).

\section{Analytical procedures}

We digitized the outline of the nuclei of the BG and the location of labeled neurons with the MD-Plot 5 system (Accustage, Shoreview, MN, USA) attached to the microscope system. Neuronal labeling was plotted on tracings of equidistant coronal sections (separated by $300-\mu \mathrm{m}$ ) throughout the BG. To examine the distribution and density of labeled neurons in the internal and external segments of the globus pallidus (GPi and GPe), we created two-dimensional density maps with a custom-made program that operates on Matlab (Mathworks, Natick, MA, USA). To create the density maps of the GPi, we first drew a curved line on each coronal section along the border between the inner and the outer portion of the GPi (Fig. 5A). Subsequently, labeled GPi neurons were projected onto the line, and both the line and the labeled neurons were unfolded and aligned on the ventral edges of the nucleus (Fig. 5B). Finally, to construct the density maps, we aligned the labeled neurons in each section (with $300-\mu \mathrm{m}$ intervals) in the rostrocaudal direction and counted the number of the labeled neurons in each of 300 
$\times 300 \mu \mathrm{m}^{2}$ bins. To create the density maps of the GPe, we drew a curved line on each coronal section midway between the medial and the lateral outline of the GPe (Fig. 8A).

The subsequent unfolding procedures (Fig. 8B) were as for the GPi. A color code in each map of the GPi and GPe was assigned to each bin to indicate the number of labeled neurons included (Figs. 5C, D and 8C, D).

\section{Safety issues}

Experiments involving the rabies virus were performed in a special primate

laboratory (biosafety level 2) designated for in vivo infectious experiments. Throughout the experiments, the monkeys were housed in individual cages that were installed inside a special biosafety cabinet. To avoid accidental infection with the virus, all investigators received immunizations beforehand and wore protective clothing during the experimental sessions. Equipment was disinfected with $80 \%$ (v/v) ethanol after each experimental session, and waste was autoclaved prior to disposal.

\section{Results}




\section{Rabies injections into the PMv}

The injection sites of rabies virus were determined according to the results from our previous electrophysiological studies (see Hoshi \& Tanji, 2002, 2006; Yamagata et al., 2009). In these studies, we found that PMv neurons located in the ventral aspect of the genu of the arcuate sulcus preferentially represent the target site, regardless of the right or left arm use, during the preparation of reaching movement. Based on this finding, two injection tracks (approximately $1 \mathrm{~mm}$ apart) were targeted at this portion of the PMv; the sites were situated 1-2 mm posterior to the genu of the arcuate sulcus and 1-2 $\mathrm{mm}$ lateral to the spur of the arcuate sulcus (Fig. 1B-D). At the 3-day post-injection period, labeled neurons were densely distributed around the injection sites (Fig. 1E, F).

The survival time after the rabies injections was set to allow either the second-order or the third-order neuron labeling across two or three synapses, respectively: (1) the first-order neurons from the PMv were located in the ventral nuclei (e.g., VLo, VApc) and mediodorsal nucleus of the thalamus (Morel et al., 2005); (2) the second-order and third-order neurons from the PMv were located in the BG 3 or 4 days after the rabies injections, respectively. For instance, Figure 2A, B show examples of labeled neurons 
observed in the GPi and $\mathrm{SNr}$ at the 3-day post-injection period (second-order neurons).

Figure $2 \mathrm{C}$ shows examples of labeled neurons observed in the GPe at the 4-day

post-injection period (third-order neurons). Summary of the number of labeled neurons

for each nucleus is shown in Figure 3.

\section{Origins of multisynaptic projections to the PMv from the GPi and SNr}

Three days after the rabies injections into the PMv, the second-order neurons were

seen in both the GPi and the SNr in two cases (Figs. 4 and 6). The number of labeled

neurons in the outer portion of the GPi was 267 on average (257 cells in Case 1 and 277

cells in Case 2), while that in the inner portion of the GPi was 146 on average (111 cells

in Case 1 and 181 cells in Case 2, Fig. 3). In order to examine the distribution of the

labeled neurons within the GPi, two-dimensional density maps were made (Fig. 5A, B).

These maps indicated that the origin of the projection to the PMv consisted of two parts

of the GPi; one was the caudodorsal part, and the other was the ventral part (Fig. 5C,

D).

Labeled neurons in the $\mathrm{SNr}$ were found widely throughout the entire rostrocaudal 
extent of the nucleus (Fig. 6). At the rostral level, the labeled neurons were located in the dorsolateral part (Fig. 6A, B, A', B'), while in the caudal two-thirds of the $\mathrm{SNr}$, the labeled neurons were distributed primarily in the central part (Fig. 6C-F, C'-F'). The number of labeled neuron in the $\mathrm{SNr}$ was 203 on average (307 cells in Case 1 and 99 cells in Case 2, Fig. 3).

Origins of multisynaptic projections to the PMv from the GPe, STN, and striatum

By extending the post-injection survival period to 4 days, we detected neuronal labeling in the GPe, STN, and striatum. In the GPe, labeled neurons were widely distributed over the nucleus (Fig. 7). In order to examine the distribution of labeled neurons, two-dimensional density maps of the GPe were made in two cases. In both cases, the labeled neurons were located not only in the rostroventral portion, but also in the dorsoventrally middle portion at the caudal level (Fig. 8). The number of labeled neurons in the GPe was 2,562 on average (2,332 cells in Case 3 and 2,792 cells in Case 4, Fig. 3).

Labeled neurons in the STN were observed extensively throughout the entire 
rostrocaudal extent of the nucleus (Fig. 9). The labeled neurons were distributed primarily in the central to dorsolateral portions of the caudal half of the nucleus (Fig.

9C-F, C'-F'). Another focus of the labeled neurons was seen in the ventromedial portion mainly at the rostral level of the nucleus (Fig. 9A, B, A', B'). The number of labeled neurons in the STN was 1,679 on average (1,583 cells in Case 3 and 1,774 cells in Case 4, Fig. 3).

In the striatum, a large number of labeled neurons were observed (Fig. 10). At the level rostral to the anterior commissure (ac; Fig. 10A-C, A'-C'), labeled neurons were located in the ventral striatum. At the level caudal to the ac (Fig. 10D-F, D'-F'), labeled neurons were found at the dorsoventrally middle portion of the medial and lateral aspects of the putamen. Further, throughout the entire rostrocaudal extent of the striatum except for the anterior-most level (Fig. 10A-E, A'-E'), labeled neurons were continuously seen in the striatal cell bridge region and in adjacent regions of the caudate nucleus and the putamen. The number of labeled neuron in the caudate nucleus including the bride region was 2,890 on average (3,431 cells in Case 3 and 2,289 cells in Case 4), and that in the putamen was 24,036 on average (27,815 cells in Case 3 and 
20,256 cells in Case 4, Fig. 3).

\section{Discussion}

We examined the organization of multisynaptic projections from the BG to the forelimb region of the PMv in macaque monkeys. After injecting rabies virus into the PMv, we found the second-order neuron labeling in the GPi and SNr. Subsequently, the third-order neuron labeling occurred in the GPe, STN, and striatum. Our histological analysis of the distributions of rabies-labeled neurons revealed that the PMv primarily receives major input signals from multiple territories within each structure of the BG that have comprised the two distinct motor territories (i.e., the primary and higher-order motor territories) and the limbic territory.

Multisynaptic inputs to the PMv from the primary motor territory of the GPi and

striatum

In the present study, we obtained many pieces of evidence indicating that the PMv

receives inputs from the two distinct motor territories (i.e., the primary and higher-order 
motor territories) of the BG. We first discuss the organization of the inputs from the

primary motor territory.

We observed that two different parts of the GPi give rise to disynaptic projections to the PMv. The first part was located in the ventral aspect of the GPi. Several lines of evidence have shown that this ventral part is interconnected predominantly with the primary motor cortex (M1). First, anatomical studies using retrograde transsynaptic transport of neurotropic viruses have revealed that the ventral part of the GPi projects multisynaptically to the M1 via the motor thalamus (Hoover \& Strick, 1993, 1999). Second, by examining the responses of GPi and GPe neurons to cortical and striatal electrical stimulations, Yoshida et al. (1993) identified pallidal neurons that receive inputs from the M1, PMv, PMd, the supplementary motor area (SMA), and the prefrontal cortex. They found that neurons in the ventral part of the GPi receive input preferentially from the M1. Third, Haber et al. $(1990,1993,1995,2000)$ have revealed that the ventrolateral GPi receives input from the dorsolateral putamen, which corresponds to the zone that receives major input from the arm region of the M1 (Takada et al., 1998a, b; Kaneda et al., 2002). These findings indicate that the PMv 
receives disynaptic input from the primary motor territory located in the ventral aspect of the GPi. Within the striatum, the third-order neurons were distributed in the putamen caudal to the ac. One group of dense patches of labeled neurons was seen in the dorsoventrally middle portion of the lateral aspect of the putamen. It has been shown that this portion of the putamen receives major input from the arm region of the M1 (Zemanick et al., 1991; Inase et al., 1996b; Takada et al., 1998a, b; Kaneda et al., 2002). These observations indicate that the PMv receives input from the primary motor territory of the striatum. The overall results provide evidence that the PMv receives multisynaptic inputs from the primary motor territories of the GPi and striatum.

Multisynaptic inputs to the PMv from the higher-order motor territory of the GPi and striatum

The second part of the GPi that sends disynaptic projections to the PMv was identified in the caudodorsal aspect of the nucleus. The previous study of Yoshida et al. (1993) have revealed that neurons in the caudodorsal part of the GPi respond primarily to electrical stimulation of the PMd, SMA, the cingulate motor area, or PMv. In our 
prior study, Saga et al. (2011) found that GPi neurons projecting to the PMdc (i.e., the caudal aspect of area F2) were located dorsal to those projecting to the M1 (Hoover \& Strick, 1993,1999). Moreover, the neurons in the caudodorsal part of the GPi have been shown to project to the SMA across synapses (Akkal et al., 2007). These findings suggest that this part of the GPi may correspond to a higher-order motor territory, and that the PMv receives input from such a territory across synapses. Within the striatum, a subset of the third-order neurons was distributed in the medial aspect of the putamen, including the striatal cell bridge region. Takada et al. (1998a, b) have revealed that this part of the striatum receives major inputs from the arm regions of the PMv, PMd, and SMA. In our prior study (Saga et al., 2011), rabies injections into the PMdc produced retrograde neuronal labeling in the same striatal zone. These findings indicate that the medial aspect of the putamen corresponds to a higher-order motor territory, and that the PMv receives input from this striatal territory across synapses. The overall results provide evidence that the PMv receives inputs from the higher-order motor territories of the GPi and striatum. 


\section{Multisynaptic inputs to the PMv from the limbic territory of the GPe and striatum}

In the present study, we found that labeled neurons in the GPe were located mainly

in the dorsoventrally middle portion at the caudal level and in the rostroventral portion.

Many pioneer works reported that neurons in the former portion of the GPe responded

to reaching or passive arm/wrist movements in monkeys (Iansek \& Porter, 1980;

DeLong et al., 1985; Filion et al., 1988; Hamada et al., 1990; Yoshida et al., 1993).

Anatomical studies have revealed that this portion of the GPe receives inputs from the

primary motor and premotor cortical areas via the striatum (Flaherty \& Graybiel, 1993;

Takada et al. 1998b; Kaneda et al. 2002, François et al., 2004). Further, Grabli et al.

(2004) have shown that the bicuculline ( $\mathrm{GABA}_{\mathrm{A}}$ receptor antagonist) microinjection

into this portion of the GPe induces abnormal movements. These observations indicate

that this portion of the GPe corresponds to its motor territory.

Moreover, Grabli et al. (2004) have shown that microinjection of bicuculline into

the rostroventral portion of the GPe of monkeys induces a stereotypic behavior, such as

obsessively licking and biting fingers. Subsequently, by injecting an anterograde tracer

into the same portion of the GPe, François et al. (2004) demonstrated that the 
rostroventral portion portion of the GPe projected to the ventromedial portion of the

$\mathrm{SNr}$ at its rostral level, which receives ample input from the ventral striatum, including

the nucleus accumbens (Haber et al., 1990, 1993, 2000). These findings indicate the

rostroventral portion of the GPe corresponds to its limbic territory. In addition, a

number of labeled neurons were distributed in the limbic territory of the striatum,

including the ventromedial putamen and the nucleus accumbens. Previous studies

reported the existence of neuronal labeling in the ventral striatum after rabies injection

into the M1 (Kelly \& Strick, 2004; Miyachi et al., 2006) and the PMd (Saga et al.,

2011). This indicates that the ventral striatum sends diverse output projections to

multiple motor cortical areas across synapses. Altogether, our findings have revealed

that the PMv receives inputs from the limbic territories of the BG (i.e., the GPe and

striatum). However, the exact pathways toward the PMv from the GPe and stratum still

remain elusive. One potential candidate is the basal forebrain; it has been shown that the

ventral striatum projects to the basal forebrain and cholinergic neurons therein in turn

sends widespread outputs to the cerebral cortex (Kievit \& Kuypers, 1975; Mesulam et

al., 1983; Haber et al., 1993, 1995; Miyachi et al., 2006). Actually, we found many 
labeled neurons in the basal forebrain in our second-order samples. Further work is needed to address this issue.

\section{Multisynaptic inputs to the PMv from the SNr and STN}

We found the second-order labeled neurons in the SNr. A subset of labeled neurons

was located in the central and dorsal portions of the SNr. These portions correspond to a sector that receives inputs from the M1- and/or SMA-recipient regions of the striatum

(Haber et al., 2000; Kaneda et al., 2002). Furthermore, these portions have been shown to project to the PMd (Saga et al., 2011), as well as to the prefrontal cortex (Middleton \& Strick, 2002), across synapses. The overall findings suggest that the PMv may receive inputs from the primary and higher-order motor territories of the $\mathrm{SNr}$.

Within the STN, we found that a subset of labeled neurons were located in the central to lateral portions within the caudal half of the nucleus. Previous studies have revealed that these portions of the STN correspond to the somatomotor territory (Nambu et al., 1996, 1997; Inase et al., 1999; Takada et al., 2001; Kaneda et al., 2002) that receives input from the M1 and sends output to the M1 across synapses. Further, 
Nambu et al. $(1996,1997)$ showed that terminal labeling from the PMv, PMd, and SMA, as well as from the M1, was located in the same portions of the STN. Thus, the overall data indicate that the PMv receives inputs from the primary and higher-order motor territories of the STN. Another subset of labeled neurons was seen in the ventromedial portion of the rostral aspect of the nucleus. This portion of the rostral STN has been shown to correspond to the limbic territory (Haber et al., 2000; Hamani et al., 2004). By injecting an anterograde tracer into the ventromedial GPe, François et al. (2004) demonstrated that this GPe region projected to the ventromedial portion of the rostral STN. Altogether, neuronal labeling in the two distinct portions of the STN indicates that the PMv receives inputs from the primary/higher-order motor territories and the limbic territory of the STN.

\section{Integration of diverse signals in the cortico-basal ganglia circuits}

We have revealed that the cellular origins of multisynaptic projections from the BG to the PMv consist of two distinct motor territories, i.e., the primary and higher-order motor territories. Seminal studies have reported that the PMv is involved in spatial 
attention (Kubota \& Hamada, 1978; Rizzolatti et al., 1981; Boussaoud \& Wise, 1993a;

Godschalk et al., 1995) and reaching execution (Boussaoud \& Wise, 1993b; Kurata \&

Hoshi, 2002; Schwartz et al., 2004). Lesion studies in monkeys have supported these

findings. The monkeys with hemi-ablation of the PMv resulted in deficits in orienting

responses toward the contralateral space (Rizzolatti et al., 1983; Scheiber, 2000).

Similarly, microinjection of bicucullin into the dorsal GPe, including a portion from

which the PMv receives input, induced attentional bias toward the contralateral space

(Grabli et al., 2004), and dopamine depletion in one side of the BG resulted in visual

hemi-neglect (Apicella et al., 1991; Miyashita et al., 1995). Thus, the PMv may

intensively interact with the BG for signal processing of spatial attention. In contrast, a

subset of PMv neurons exhibits movement-related activity during reaching movement.

Since the movement-related activity is most prominent in the M1 (Evarts, 1968;

Georgopoulos et al., 1982; Tanji \& Kurata, 1982), the PMv may receive the information

about the movement from the primary motor territory of the BG. In addition to spatial

attention and movement execution, the PMv has been shown to participate in

visuomotor transformation for reaching movement by encoding both visuospatial and 
motor information (Boussaoud \& Wise, 1993a, b; Kurata \& Hoshi, 2002). Actually, inactivation of the PMv induced deficits in remapping from visual to motor space in shift-prism adaptation (Kurata \& Hoshi, 1999). One intriguing possibility is that the PMv receives two distinct inputs concerning movement execution from the primary motor territory and spatial attention (or visual signals) from the higher-order motor territory of the $\mathrm{BG}$, and that these two sets of information are integrated in the PMv to achieve the visuomotor transformation. After the motor commands are generated for the reaching movement, these signals may be transferred to the M1 via the intracortical connections between the PMv and the M1 (Dum \& Strick, 2005; Dancause et al., 2006) and via the circuits through the BG. In addition to the reaching movement, the PMv plays a crucial role in goal-directed grasping movements (Rizzolatti et al., 1987). Inactivation of the PMv impairs grasping movements without any paralysis of finger movements per se (Fogassi et al., 2001). Murata et al. (1997) have reported that PMv neurons reflect three-dimensional features of objects for grasping them. In the parietal and temporal cortical areas, object visual signals are amply represented in the inferior parietal lobule (IPL) and the inferotemporal cortex (IT). Of these the PMv is directly 
interconnected with the IPL, but not with the IT (Luppino et al., 2001; Rozzi et al., 2006; Borra et al., 2008). Anatomical studies have revealed that the IT projects to the IPL, suggesting that the PMv may receive input from the IT via the IPL. In addition, it has been reported that the IT projects not only to the caudate tail (Saint-Cyr et al., 1990; Cheng et al., 1997), but also to the lateral aspect of the caudate body (Webster et al., 1993) in which we found the cellular origin of the projection to the PMv. Thus, the PMv may receive signals about the object shape represented in the IT via the BG. Taken together with the electrical stimulation and mapping studies (Gentilucci et al., 1988;

Godschalk et al., 1995; Aflalo \& Graziano, 2006; Maranesi et al., 2012), these findings revealed a large overlap of zones representing reaching and grasping movements in the

PMv. The overlap region may integrate movements with motor commands to achieve

the visuomotor integration for grasping a target. An intriguing possibility is that the PMv-BG networks may be involved in the integration of the reaching and grasping components of forelimb movement (Gerbella et al., 2015).

The motivational aspect, as well as the visual aspect, has been shown to influence action (Mogenson et al., 1980; Haber et al., 2000). In relation to this, it has been 
revealed that the motor territory of the BG represents 'the vigor of movement'.

Inactivation of the caudoventral part of the GPi (i.e., the primary motor territory)

resulted in the increase in the reaction time of a visually guided reaching task (Inase et al., 1996a), the reduction in the movement velocity and the acceleration without impairment in reaching execution (Wenger et al., 1999; Turner \& Desmurget, 2010), and the undershoot toward motor targets (Turner \& Anderson, 2005; Desmurget \& Turner, 2008). These observations indicate that the motor territory of the BG already integrates the information concerning the visuospatial and motivational aspects. Thus, the PMv may receive the integrated 'vigor' signals from the motor territory of the BG (Turner \& Desmurget, 2010). In addition to this, the limbic territory of the BG may provide the PMv with context-dependent motivational signals. Actually, Roesch and Olson (Roesch \& Olson, 2004) showed that PMv neurons in macaque monkeys fired more strongly when the expected reward or penalty was larger, indicating that the PMv represents a general motivational signal of action. One intriguing possibility is that the PMv may receive it from the limbic territory of the BG. Altogether, it is likely that the PMv receives the information not only concerning the visual and motor aspects and 
response vigor, but also about general motivation from the BG. Further, the

motivational signal from the BG may enhance other types of forelimb movements in foraging behavior, such as locomotion, climbing, and reaching/grasping to eat food (Graziano, 2006; Rizzolatti et al., 2014; Wise, 2006).

\section{Comparison of the BG labeling after PMv and PMd injections}

The PMd and PMv are suggested to play distinct roles in achievement of reaching

and grasping movements. It has been shown that the PMd plays a major role in action

planning based on multiple sets of sensory-motor association (i.e., indirect specification

of action), whereas the PMv is involved more highly in matching actions directly with

features (e.g., shape and location) of a target (i.e., direct guidance of action) (Hoshi \&

Tanji, 2007). In a prior report, we investigated the origins of mutisynaptic inputs in the

BG to the PMd (Saga et al., 2011). By comparing the results obtained after the PMd and

PMv injection, it was found that the number of labeled neurons in the output station of

the BG (i.e., GPi and SNr) was comparable in the PMd and PMv injection cases,

whereas those in the intermediate (i.e., GPe and STN) and input (i.e., striatum) stations 
were higher in the PMv injection case than in the PMd injection case (Saga et al., 2011).

These findings might suggest that the PMv is more tightly linked with the indirect

pathway (involving the GPe and STN) than the PMd, and that the greater degree of

funneling takes place in the striatum in the PMv-BG circuit than in the PMd-BG circuit.

However, such notions should be taken as a preliminary account because the subjects,

injection volumes, and viral lots differ in the PMd and PMv injections. To better

characterize possible differences in the network architecture of the PMv-BG and

PMd-BG circuits, it is needed to overcome these technical issues.

\section{Acknowledgements}

We thank T. Ogata and T. Kuroda for technical assistance. This work was supported by

CREST, JST (E. H. and M. T.), and a Grant-in Aid for Young Scientists KAKENHI

70728162 (H. I.) from Japan Society for Promotion of Science.

Abbreviations [alphabetic order]

Anterior commissure (ac), Basal ganglia (BG), Dorsal premotor cortex (PMd), Globus 
pallidus external segment (GPe), Globus pallidus internal segment (GPi), Primary motor cortex (M1), Substantia nigra pars reticulata (SNr), Subthalamic nucleus (STN),

Supplementary motor cortex (SMA), Ventral premotor cortex (PMv)

\section{References}

Aflalo, T.N. \& Graziano, M.S.A. (2006) Possible origins of the complex topographic organization of motor cortex: Reduction of a multidimensional space onto a two-dimensional array. J. Neurosci., 26, 6288-6297.

Akkal, D., Dum, R.P., \& Strick, P.L. (2007) Supplementary motor area and presupplementary motor area: targets of basal ganglia and cerebellar output. $J$. Neurosci., 27, 10659-10673.

Alexander, G.E. \& Crutcher, M.D. (1990) Functional architecture of basal ganglia circuits: neural substrates of parallel processing. Trends Neurosci., 13, 266-271.

Apicella, P., Legallet, E., Nieoullon, A., \& Trouche, E. (1991) Neglect of contralateral visual stimuli in monkeys with unilateral striatal dopamine depletion. Behav. Brain Res., 46, 187-195.

Barbas, H. \& Pandya, D.N. (1987) Architecture and frontal cortical connections of the premotor cortex (area 6) in the rhesus monkey. J. Comp. Neurol., 256, 211-228.

Barbas, H., \& García-Cabezas, M. Á. (2015). Motor cortex layer 4: less is more. Trends in Neurosci., 38, 259-261.

Borra, E., Belmalih, A., Calzavara, R., Gerbella, M., Murata, A., Rozzi, S., \& Luppino, G. (2008) Cortical connections of the macaque anterior intraparietal (AIP) area. Cereb. Cortex, 18, 1094-1111.

Boussaoud, D. \& Wise, S.P. (1993a) Primate frontal cortex: neuronal activity following attentional versus intentional cues. Exp. Brain Res., 95, 15-27.

Boussaoud, D. \& Wise, S.P. (1993b) Primate frontal cortex: effects of stimulus and movement. Exp. Brain Res., 95, 28-40. 
Caminiti, R., Johnson, P.B., Galli, C., Ferraina, S., \& Burnod, Y. (1991) Making arm movements within different parts of space: the premotor and motor cortical representation of a coordinate system for reaching to visual targets. J. Neurosci., 11, 1182-1197.

Cheng, K., Saleem, K.S., \& Tanaka, K. (1997) Organization of corticostriatal and corticoamygdalar projections arising from the anterior inferotemporal area TE of the macaque monkey: a Phaseolus vulgaris leucoagglutinin study. J. Neurosci., 17, $7902-7925$.

Dancause, N., Barbay, S., Frost, S.B., Plautz, E.J., Popescu, M., Dixon, P.M., Stowe, A.M., Friel, K.M., \& Nudo, R.J. (2006) Topographically divergent and convergent connectivity between premotor and primary motor cortex. Cereb. Cortex, 16, $1057-$ 1068.

DeLong, M.R., Crutcher, M.D., \& Georgopoulos, A.P. (1985) Primate globus pallidus and subthalamic nucleus: functional organization. J. Neurophysiol., 53, 530-543.

Desmurget, M. \& Turner, R.S. (2008) Testing basal ganglia motor functions through reversible inactivations in the posterior internal globus pallidus. J. Neurophysiol., 99, 1057-1076.

Dum, R.P. \& Strick, P.L. (2005) Frontal lobe inputs to the digit representations of the motor areas on the lateral surface of the hemisphere. J. Neurosci., 25, 1375-1386.

Evarts, E.V. (1968) Relation of pyramidal tract activity to force exerted during voluntary movement. J. Neurophysiol., 31, 14-27.

Filion, M., Tremblay, L., \& Bédard, P.J. (1988) Abnormal influences of passive limb movement on the activity of globus pallidus neurons in parkinsonian monkeys. Brain Res., 444, 165-176.

Flaherty, A.W. \& Graybiel, A.M. (1993) Two input systems for body representations in the primate striatal matrix: experimental evidence in the squirrel monkey. $J$.

Neurosci., 13, 1120-1137.

Fogassi, L., Gallese, V., Buccino, G., Craighero, L., Fadiga, L., \& Rizzolatti, G. (2001) Cortical mechanism for the visual guidance of hand grasping movements in the monkey: A reversible inactivation study. Brain, 124, 571-586.

François, C., Grabli, D., McCairn, K., Jan, C., Karachi, C., Hirsch, E.-C., Féger, J., \& Tremblay, L. (2004) Behavioural disorders induced by external globus pallidus dysfunction in primates II. Anatomical study. Brain, 127, 2055-2070. 
García-Cabezas, M. Á., \& Barbas, H. (2014). Area 4 has layer IV in adult primates. Eur. J. Neurosci., 39, 1824-1834.

Gentilucci, M., Fogassi, L., Luppino, G., Matelli, M., Camarda, R., \& Rizzolatti, G. (1988) Functional organization of inferior area 6 in the macaque monkey. Exp. Brain Res., 71, 475-490.

Georgopoulos, A.P., Kalaska, J.F., Caminiti, R., \& Massey, J.T. (1982) On the relations between the direction of two-dimensional arm movements and cell discharge in primate motor cortex. J. Neurosci., 2, 1527-1537.

Gerbella, M., Borra, E., Mangiaracina, C., Rozzi, S., \& Luppino, G. (2015) Corticostriate Projections from Areas of the "Lateral Grasping Network": Evidence for Multiple Hand-Related Input Channels. Cereb. Cortex, (in press).

Godschalk, M., Mitz, A.R., van Duin, B., \& van der Burg, H. (1995) Somatotopy of monkey premotor cortex examined with microstimulation. Neurosci. Res., 23, 269279.

Grabli, D., McCairn, K., Hirsch, E.-C., Agid, Y., Féger, J., François, C., \& Tremblay, L. (2004) Behavioural disorders induced by external globus pallidus dysfunction in primates: I. Behavioural study. Brain, 127, 2039-2054.

Graziano, M. (2006) The organization of behavioral repertoire in motor cortex. Annu. Rev. Neurosci, 29, 105-134.

Haber, S.N., Fudge, J.L., \& McFarland, N.R. (2000) Striatonigrostriatal pathways in primates form an ascending spiral from the shell to the dorsolateral striatum. $J$. Neurosci., 20, 2369-2382.

Haber, S.N., Kunishio, K., Mizobuchi, M., \& Lynd-Balta, E. (1995) The orbital and medial prefrontal circuit through the primate basal ganglia. J. Neurosci., 15, 48514867.

Haber, S.N., Lynd, E., Klein, C., \& Groenewegen, H.J. (1990) Topographic organization of the ventral striatal efferent projections in the rhesus monkey: An anterograde tracing study. J. Comp. Neurol., 293, 282-298.

Haber, S.N., Lynd-Balta, E., \& Mitchell, S.J. (1993) The organization of the descending ventral pallidal projections in the monkey. J. Comp. Neurol., 329, 111-128.

Halsband, U. \& Passingham, R.E. (1985) Premotor cortex and the conditions for movement in monkeys (Macaca fascicularis). Behav. Brain Res., 18, 269-277. 
Hamada, I., DeLong, M.R., \& Mano, N. (1990) Activity of identified wrist-related pallidal neurons during step and ramp wrist movements in the monkey. $J$. Neurophysiol., 64, 1892-1906.

Hamani, C., Saint-Cyr, J.A., Fraser, J., Kaplitt, M., \& Lozano, A.M. (2004) The subthalamic nucleus in the context of movement disorders. Brain, 127, 4-20.

Hashimoto, M., Takahara, D., Hirata, Y., Inoue, K.-I., Miyachi, S., Nambu, A., Tanji, J., Takada, M., \& Hoshi, E. (2010) Motor and non-motor projections from the cerebellum to rostrocaudally distinct sectors of the dorsal premotor cortex in macaques. Eur. J. Neurosci., 31, 1402-1413.

Hoover, J.E. \& Strick, P.L. (1993) Multiple output channels in the basal ganglia. Science, 259, 819-821.

Hoover, J.E. \& Strick, P.L. (1999) The organization of cerebellar and basal ganglia outputs to primary motor cortex as revealed by retrograde transneuronal transport of herpes simplex virus type 1. J. Neurosci., 19, 1446-1463.

Hoshi, E. \& Tanji, J. (2000) Integration of target and body-part information in the premotor cortex when planning action. Nature, 408, 466-470.

Hoshi, E. \& Tanji, J. (2006) Differential involvement of neurons in the dorsal and ventral premotor cortex during processing of visual signals for action planning. $J$. Neurophysiol., 95, 3596-3616.

Hoshi, E. \& Tanji, J. (2007) Distinctions between dorsal and ventral premotor areas: anatomical connectivity and functional properties. Curr. Opin. Neurobiol., 17, 234242.

Iansek, R. \& Porter, R. (1980) The monkey globus pallidus: neuronal discharge properties in relation to movement. $J$. Physiol., 301, 439-455.

Inase, M., Buford, J.A., \& Anderson, M.E. (1996a) Changes in the control of arm position, movement, and thalamic discharge during local inactivation in the globus pallidus of the monkey. J. Neurophysiol., 75, 1087-1104.

Inase, M., Sakai, S.T., \& Tanji, J. (1996b) Overlapping corticostriatal projections from the supplementary motor area and the primary motor cortex in the macaque monkey: an anterograde double labeling study. J. Comp. Neurol., 373, 283-296.

Inase, M., Tokuno, H., Nambu, A., Akazawa, T., \& Takada, M. (1999) Corticostriatal and corticosubthalamic input zones from the presupplementary motor area in the 
macaque monkey: comparison with the input zones from the supplementary motor area. Brain Res., 833, 191-201.

Kalaska, J.F. \& Crammond, D.J. (1992) Cerebral cortical mechanisms of reaching movements. Science, 255, 1517-1523.

Kaneda, K., Nambu, A., Tokuno, H., \& Takada, M. (2002) Differential processing patterns of motor information via striatopallidal and striatonigral projections. $J$. Neurophysiol., 88, 1420-1432.

Kelly, R.M. \& Strick, P.L. (2004) Macro-architecture of basal ganglia loops with the cerebral cortex: use of rabies virus to reveal multisynaptic circuits. Prog. Brain Res., 143, 449-459.

Kievit, J. \& Kuypers, H.G. (1975) Basal forebrain and hypothalamic connection to frontal and parietal cortex in the Rhesus monkey. Science, 187, 660-662.

Kubota, K. \& Hamada, I. (1978) Visual tracking and neuron activity in the post-arcuate area in monkeys. J. Physiol. (Paris), 74, 297-312.

Kurata, K. \& Wise, S.P. (1988) Premotor cortex of rhesus monkeys: set-related activity during two conditional motor tasks. Exp. Brain Res., 69, 327-343.

Kurata, K. (1993) Premotor cortex of monkeys: set-and movement-related activity reflecting amplitude and direction of wrist movements. J. Neurophysiol., 69, 187187.

Kurata, K. \& Hoffman, D.S. (1994) Differential effects of muscimol microinjection into dorsal and ventral aspects of the premotor cortex of monkeys. J. Neurophysiol., 71, 1151-1164.

Kurata, K. \& Hoshi, E. (1999) Reacquisition deficits in prism adaptation after muscimol microinjection into the ventral premotor cortex of monkeys. J. Neurophysiol., 81, 1927-1938.

Kurata, K. \& Hoshi, E. (2002) Movement-related neuronal activity reflecting the transformation of coordinates in the ventral premotor cortex of monkeys. $J$. Neurophysiol., 88, 3118-3132.

Luppino, G., Calzavara, R., Rozzi, S., \& Matelli, M. (2001) Projections from the superior temporal sulcus to the agranular frontal cortex in the macaque. Eur. J. Neurosci., 14, 1035-1040. 
Luppino, G., Murata, A., Govoni, P., \& Matelli, M. (1999) Largely segregated parietofrontal connections linking rostral intraparietal cortex (areas AIP and VIP) and the ventral premotor cortex (areas F5 and F4). Exp. Brain Res., 128, 181-187.

Maranesi, M., Rodà, F., Bonini, L., Rozzi, S., Ferrari, P.F., Fogassi, L., \& Coudé, G. (2012) Anatomo-functional organization of the ventral primary motor and premotor cortex in the macaque monkey. Eur. J. Neurosci., 36, 3376-3387.

Matelli, M., Camarda, R., Glickstein, M., \& Rizzolatti, G. (1986) Afferent and efferent projections of the inferior area 6 in the macaque monkey. J. Comp. Neurol., 251, 281-298.

Matelli, M., Govoni, P., Galletti, C., Kutz, D.F., \& Luppino, G. (1998) Superior area 6 afferents from the superior parietal lobule in the macaque monkey. J. Comp. Neurol., 402, 327-352.

Matelli, M., Luppino, G., \& Rizzolatti, G. (1985) Patterns of cytochrome oxidase activity in the frontal agranular cortex of the macaque monkey. Behav. Brain Res., 18, 125-136.

Mesulam, M.M., Mufson, E.J., Levey, A.I., \& Wainer, B.H. (1983) Cholinergic innervation of cortex by the basal forebrain: cytochemistry and cortical connections of the septal area, diagonal band nuclei, nucleus basalis (substantia innominata), and hypothalamus in the rhesus monkey. J. Comp. Neurol., 214, 170-197.

Middleton, F.A. \& Strick, P.L. (2002) Basal-ganglia "projections" to the prefrontal cortex of the primate. Cereb. Cortex, 12, 926-935.

Miyachi, S., Lu, X., Imanishi, M., Sawada, K., Nambu, A., \& Takada, M. (2006) Somatotopically arranged inputs from putamen and subthalamic nucleus to primary motor cortex. Neurosci. Res., 56, 300-308.

Miyashita, N., Hikosaka, O., \& Kato, M. (1995) Visual hemineglect induced by unilateral striatal dopamine deficiency in monkeys. Neuroreport, 6, 1257-1260.

Mogenson, G.J., Jones, D.L., \& Yim, C.Y. (1980) From motivation to action: functional interface between the limbic system and the motor system. Prog. Neurobiol, 14, 69-97.

Morel, A., Liu, J., Wannier, T., Jeanmonod, D., \& Rouiller, E.M. (2005) Divergence and convergence of thalamocortical projections to premotor and supplementary motor cortex: a multiple tracing study in the macaque monkey. Eur. J. Neurosci., 21, 1007-1029. 
Murata, A., Fadiga, L., Fogassi, L., Gallese, V., Raos, V., \& Rizzolatti, G. (1997) Object representation in the ventral premotor cortex (area F5) of the monkey. $J$. Neurophysiol., 78, 2226-2230.

Nambu, A., Takada, M., Inase, M., \& Tokuno, H. (1996) Dual somatotopical representations in the primate subthalamic nucleus: evidence for ordered but reversed body-map transformations from the primary motor cortex and the supplementary motor area. J. Neurosci., 16, 2671-2683.

Nambu, A., Tokuno, H., Inase, M., \& Takada, M. (1997) Corticosubthalamic input zones from forelimb representations of the dorsal and ventral divisions of the premotor cortex in the macaque monkey: comparison with the input zones from the primary motor cortex and the supplementary motor area. Neurosci. Lett., 239, 1316.

Petrides, M. \& Pandya, D.N. (1999) Dorsolateral prefrontal cortex: comparative cytoarchitectonic analysis in the human and the macaque brain and corticocortical connection patterns. Eur. J. Neurosci., 11, 1011-1036.

Parent, A. \& Hazrati, L.-N. (1995a) Functional anatomy of the basal ganglia. I. The cortico-basal ganglia-thalamo-cortical loop. Brain Res. Rev., 20, 91-127.

Parent, A. \& Hazrati, L.-N. (1995b) Functional anatomy of the basal ganglia. II. The place of subthalamic nucleus and external pallidium in basal ganglia circuitry.

Brain Rese. Rev., 20, 128-154.

Raos, V., Franchi, G., Gallese, V., \& Fogassi, L. (2003) Somatotopic organization of the lateral part of area F2 (dorsal premotor cortex) of the macaque monkey. $J$. Neurophysiol., 89, 1503-1518.

Raos, V., Umiltà, M.A., Gallese, V., \& Fogassi, L. (2004) Functional properties of grasping-related neurons in the dorsal premotor area $\mathrm{F} 2$ of the macaque monkey. $J$. Neurophysiol., 92, 1990-2002.

Raos, V., Umiltà, M.A., Murata, A., Fogassi, L., \& Gallese, V. (2006) Functional properties of grasping-related neurons in the ventral premotor area F5 of the macaque monkey. J. Neurophysiol., 95, 709-729.

Rizzolatti, G., Cattaneo, L., Fabbri-Destro, M., \& Rozzi, S. (2014) Cortical mechanisms underlying the organization of goal-directed actions and mirror neuron-based action understanding. Physiol. Rev., 94, 655-706. 
Rizzolatti, G., Gentilucci, M., Fogassi, L., Luppino, G., Matelli, M., \& Ponzoni-Maggi, S. (1987) Neurons related to goal-directed motor acts in inferior area 6 of the macaque monkey. Exp. Brain Res., 67, 220-224.

Rizzolatti, G., Luppino, G., \& Matelli, M. (1998) The organization of the cortical motor system: new concepts. Electroencephalogr Clin. Neurophysiol., 106, 283-296.

Rizzolatti, G., Matelli, M., \& Pavesi, G. (1983) Deficits in attention and movement following the removal of postarcuate (area 6) and prearcuate (area 8) cortex in macaque monkeys. Brain, 106 (Pt 3), 655-673.

Rizzolatti, G., Scandolara, C., Matelli, M., \& Gentilucci, M. (1981) Afferent properties of periarcuate neurons in macaque monkeys. II. Visual responses. Behav. Brain Res., 2, 147-163.

Roesch, M.R. \& Olson, C.R. (2004) Neuronal activity related to reward value and motivation in primate frontal cortex. Science, 304, 307-310.

Rozzi, S., Calzavara, R., Belmalih, A., Borra, E., Gregoriou, G.G., Matelli, M., \& Luppino, G. (2006) Cortical connections of the inferior parietal cortical convexity of the macaque monkey. Cereb. Cortex, 16, 1389-1417.

Saga, Y., Hirata, Y., Takahara, D., Inoue, K.-I., Miyachi, S., Nambu, A., Tanji, J., Takada, M., \& Hoshi, E. (2011) Origins of multisynaptic projections from the basal ganglia to rostrocaudally distinct sectors of the dorsal premotor area in macaques.

Eur. J. Neurosci., 33, 285-297.

Saint-Cyr, J.A., Ungerleider, L.G., \& Desimone, R. (1990) Organization of visual cortical inputs to the striatum and subsequent outputs to the pallido-nigral complex in the monkey. J. Comp. Neurol., 298, 129-156.

Schieber, M.H. (2000) Inactivation of the ventral premotor cortex biases the laterality of motoric choices. Exp. Brain Res., 130, 497-507.

Schwartz, A.B., Moran, D.W., \& Reina, G.A. (2004) Differential representation of perception and action in the frontal cortex. Science, 303, 380-383.

Scott, S.H., Sergio, L.E., \& Kalaska, J.F. (1997) Reaching movements with similar hand paths but different arm orientations. II. activity of individual cells in dorsal premotor cortex and parietal area 5. J. Neurophysiol., 78, 2413-2426.

Takada, M., Tokuno, H., Hamada, I., Inase, M., Ito, Y., Imanishi, M., Hasegawa, N., Akazawa, T., Hatanaka, N., \& Nambu, A. (2001) Organization of inputs from 
cingulate motor areas to basal ganglia in macaque monkey. Eur. J. Neurosci., 14, 1633-1650.

Takada, M., Tokuno, H., Nambu, A., \& Inase, M. (1998a) Corticostriatal input zones from the supplementary motor area overlap those from the contra- rather than ipsilateral primary motor cortex. Brain Res., 791, 335-340.

Takada, M., Tokuno, H., Nambu, A., \& Inase, M. (1998b) Corticostriatal projections from the somatic motor areas of the frontal cortex in the macaque monkey: segregation versus overlap of input zones from the primary motor cortex, the supplementary motor area, and the premotor cortex. Exp. Brain Res., 120, 114-128.

Takahara, D., Inoue, K.-I., Hirata, Y., Miyachi, S., Nambu, A., Takada, M., \& Hoshi, E. (2012) Multisynaptic projections from the ventrolateral prefrontal cortex to the dorsal premotor cortex in macaques - anatomical substrate for conditional visuomotor behavior. Eur. J. Neurosci., 36, 3365-3375.

Tanji, J. \& Kurata, K. (1982) Comparison of movement-related activity in two cortical motor areas of primates. J. Neurophysiol., 48, 633-653.

Turner, R.S. \& Anderson, M.E. (2005) Context-dependent modulation of movement-related discharge in the primate globus pallidus. J. Neurosci., 25, 29652976.

Turner, R.S. \& Desmurget, M. (2010) Basal ganglia contributions to motor control: a vigorous tutor. Curr. Opin. Neurobiol., 20, 704-716.

Umiltà, M.A., Brochier, T., Spinks, R.L., \& Lemon, R.N. (2007) Simultaneous recording of macaque premotor and primary motor cortex neuronal populations reveals different functional contributions to visuomotor grasp. J. Neurophysiol., 98, 488-501.

Webster, M.J., Bachevalier, J., \& Ungerleider, L.G. (1993) Subcortical connections of inferior temporal areas TE and TEO in macaque monkeys. J. Comp. Neurol., 335, 73-91.

Wenger, K.K., Musch, K.L., \& Mink, J.W. (1999) Impaired reaching and grasping after focal inactivation of globus pallidus pars interna in the monkey. J. Neurophysiol., 82, 2049-2060.

Wise, S.P. (1985) The primate premotor cortex: past, present, and preparatory. Annu. Rev. Neurosci., 8, 1-19. 
Wise, S.P. (2006) The ventral premotor cortex, corticospinal region C, and the origin of primates. Cortex, 42, 521-524.

Wise, S.P., Boussaoud, D., Johnson, P.B., \& Caminiti, R. (1997) Premotor and parietal cortex: corticocortical connectivity and combinatorial computations. Annu. Rev. Neurosci., 20, 25-42.

Yamagata, T., Nakayama, Y., Tanji, J., \& Hoshi, E. (2009) Processing of visual signals for direct specification of motor targets and for conceptual representation of action targets in the dorsal and ventral premotor cortex. J. Neurophysiol., 102, 3280-3294.

Yamawaki, N., Borges, K., Suter, B. A., Harris, K. D., \& Shepherd, G. M. G. (2014). A genuine layer 4 in motor cortex with prototypical synaptic circuit connectivity. eLife, 3, e05422.

Yoshida, S., Nambu, A., \& Jinnai, K. (1993) The distribution of the globus pallidus neurons with input from various cortical areas in the monkeys. Brain Res., 611, 170-174.

Zemanick, M.C., Strick, P.L., \& Dix, R.D. (1991) Direction of transneuronal transport of herpes simplex virus 1 in the primate motor system is strain-dependent. Proc. Natl. Acad. Sci. USA, 88, 8048-8051. 
Table 1.

Summary of experiments

\begin{tabular}{lllllll}
\hline Monkey & Species & $\begin{array}{l}\text { Injection } \\
\text { site }\end{array}$ & Tracer & $\begin{array}{l}\text { Survival } \\
\text { (days) }\end{array}$ & $\begin{array}{l}\text { Injection } \\
\text { tracks } \\
(\boldsymbol{n})\end{array}$ & $\begin{array}{l}\text { Injection } \\
\text { volume } \\
(\boldsymbol{\mu} \mathbf{L})\end{array}$ \\
\hline Case 1 & $\begin{array}{l}\text { M. } \\
\text { fuscata }\end{array}$ & PMv & CSV-11 & 3 & 2 & 2.0 \\
\hline Case 2 & $\begin{array}{l}\text { M. } \\
\text { fuscata }\end{array}$ & PMv & CSV-11 & 3 & 2 & 2.0 \\
\hline Case 3 & $\begin{array}{l}\text { M. } \\
\text { fuscata }\end{array}$ & PMv & CSV-11 & 4 & 2 & 2.0 \\
\hline Case 4 & $\begin{array}{l}\text { M. } \\
\text { fuscata }\end{array}$ & PMv & CSV-11 & 4 & 2 & 2.0 \\
\hline
\end{tabular}




\section{Figure Legends}

\section{Figure 1}

Locations of injection sites in the PMv. (A) Diagram illustrating the frontal lobe of the macaque monkey. The rectangular area drawn with broken line is enlarged in (B). (B)

Schematic view of injection site of rabies virus in the PMv. The circle drawn with the dotted line indicates the intended injection site. Within the intended injection site, the small gray circles $(0.5 \mathrm{~mm}$ in radius $)$ indicate the estimated viral spread around the injection tracks. The genu of the arcuate sulcus (AS) is denoted with the asterisk. The border between the premotor cortex and the primary motor cortex (M1) is represented by the broken line. (C) Drawing illustrating a slice with an injection track for each case.

In (C-E), an arrowhead points to an injection track. (D) Low-magnification microphotograph of a Nissl-stained section of Case 1. (E) Low-magnification microphotograph of the injection site in Case 1 three days after rabies injection. In the low-power image, labeled neurons are densely distributed around the injection site. (F) The boxed region in the panel (D) is enlarged. Many neurons are seen to be labeled in a Golgi-like manner. CS, central sulcus; PS, principal sulcus; AS, the arcuate sulcus; Spur, 
spur of AS; Spur, spur of AS; Cg, cingulate sulcus. Scale bars in (D) and (E): $500 \mu \mathrm{m}$.

Scale bar in (F): $50 \mu \mathrm{m}$.

\section{Figure 2}

Neuronal labeling in the GP and SNr. (A and B) Second-order neuron labeling in the

GPi (A) and the SNr (B) 3 days after the rabies injection into the PMv. (C) Third-order neuron labeling in the GPe 4 days after the rabies injection. The boxed region in each panel is enlarged in each microphotograph. Scale bars in A-C: $50 \mu \mathrm{m}$. oGPi, outer portion of GPi; iGPi, inner portion of GPi; $\mathrm{SNc}$, substantia nigra compacta; $\mathrm{SNr}$, sabstatia nigra reticulata.

\section{Figure 3}

Summary plot of the number of labeled neuron. Mean values of the labeled neurons in each nucleus are shown. Each data point at the top of each bar indicates the number of labeled neuron in each case (Case 1, filled circle; Case 2, open circle; Case 3, filled square; Case 4, open square). The distance between the data point and the mean 
corresponds to standard error of the mean. White bars indicate mean values of labeled neurons (second-order neurons) observed in the GPi and SNr, while gray bars indicate the mean values of the labeled neurons (third-order neurons) observed in the GPe, STN and striatum (Cd and Put). Cd, caudate nucleus; GPe, external segment of the globus pallidus; GPi, internal segment of the globus pallidus; Put, putamen; SNr, substantia nigra pars reticulata; SNT, subthalamic nucleus.

\section{Figure 4}

Distribution of labeled neurons in the GPi. Six coronal sections are arranged rostrocaudally from the left to right (A-F, $\left.A^{\prime}-F^{\prime}\right)$. Each row represents data from a single subject (Cases 1,2). Each dot indicates the location of an infected neuron labeled by retrograde transneuronal transport (second-order neurons). The border between the oGPi and the iGPi is represented with the dotted line. Scale bar: $1 \mathrm{~mm}$. oGPi, outer portion of GPi; iGPi, inner portion of GPi.

\section{Figure 5}


Density maps of GPi neurons labeled after rabies virus injections into the PMv. (A and B) Procedures to construct two-dimensional density maps of the GPi. The unfolding process started with drawing a line through the border between the outer (oGPi) and inner (iGPi) portions of the GPi. The reference points were placed at the bottom (the red circle) and the top (the blue circle) of the GPi. The position of each labeled neuron was projected onto the line. Then, each line through the nucleus was aligned on the ventral edge of the GPi (B). Neurons were divided into $300 \times 300 \mu \mathrm{m}^{2}$ bins. (C and D) Density maps of the GPi neuron labeling in each case. The number of labeled neurons in each bin was counted and color-coded.

\section{Figure 6}

Distribution of labeled neurons in the SNr. Six coronal sections are arranged rostrocaudally from the left to right (A-F, A'-F'). Each row represents data from a single subject $($ Cases 1, 2). Each dot indicates the location of an infected neuron labeled by retrograde transneuronal transport (second-order neurons). The number in each section indicates its relative rostrocaudal position within the $\mathrm{SNr}$ (most rostral level $=0$, most 
caudal level =1). The lines in each section indicate the border between the $\mathrm{SNr}$ and the substantia nigra pars compacta $(\mathrm{SNc})$.

\section{Figure 7}

Distribution of labeled neurons in the GPe (third-order neurons) and the GPi

(second-order or third-order neurons). Six coronal sections are arranged rostrocaudally

from the left to right (A-F, A'-F'). Each row represents data from a single subject (Cases

3, 4). Each dot indicates the location of an infected neuron.

\section{Figure 8}

Density maps of GPe neurons labeled after PMv injections. (A and B) Procedures to

construct two-dimensional density maps of the GPe. The unfolding process started with

drawing line through the center of the GPe. The reference points were placed at the

bottom (the red circle) and at the top (the blue circle) of the GPe. The position of each

labeled neuron was projected onto the central line. Then, each line through the nucleus

was aligned on the ventral edge of the GPe (B). Neurons were divided into $300 \times$ 
$300 \mathrm{\mu m}^{2}$ bins. (C, D) Density maps of the GPe neuron labeling in each case. The number of labeled neurons in each bin was counted and color-coded.

\section{Figure 9}

Distribution of labeled neurons in the STN. Six coronal sections are arranged

rostrocaudally from the left to right (A-F, A'-F'). Each row represents data from a single subject (Cases 3, 4).

\section{Figure 10}

Distribution of labeled neurons in the striatum. Six coronal sections are arranged

rostrocaudally from the left to right (A-F, A'-F'). Each row represents data from a single

subject (Cases 3, 4). For each section, the AP (anterior-posterior) level relative to ac (anterior commissure) is indicated in mm. Scale bar in F' applies to all panels (A-F, $\left.A^{\prime}-F^{\prime}\right)$. 
A
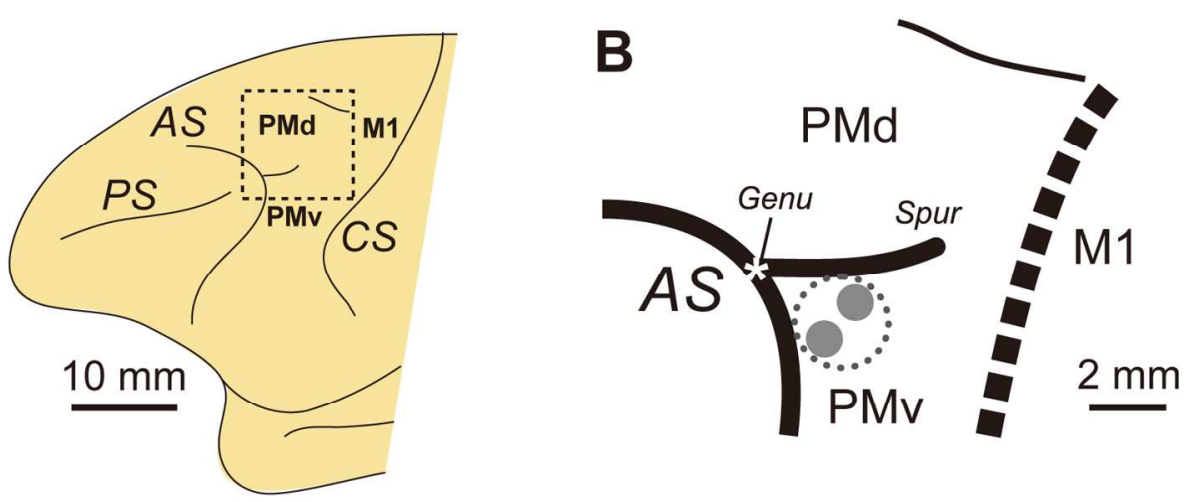

C

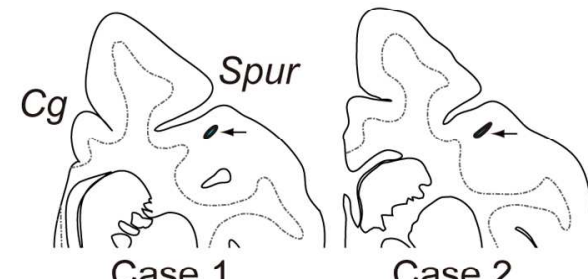

Case 1

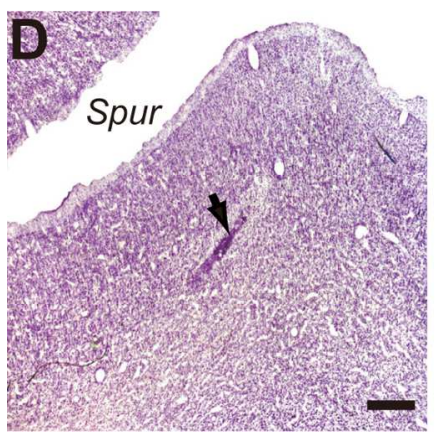

E
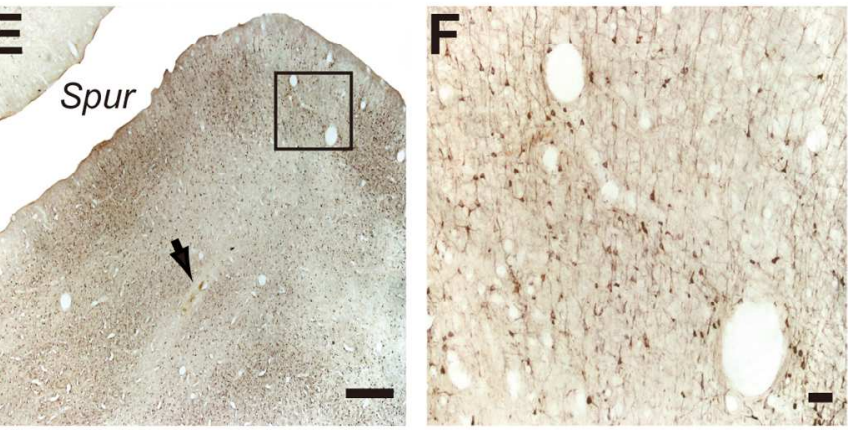

Figure 1

$144 \times 143 \mathrm{~mm}(300 \times 300$ DPI $)$ 


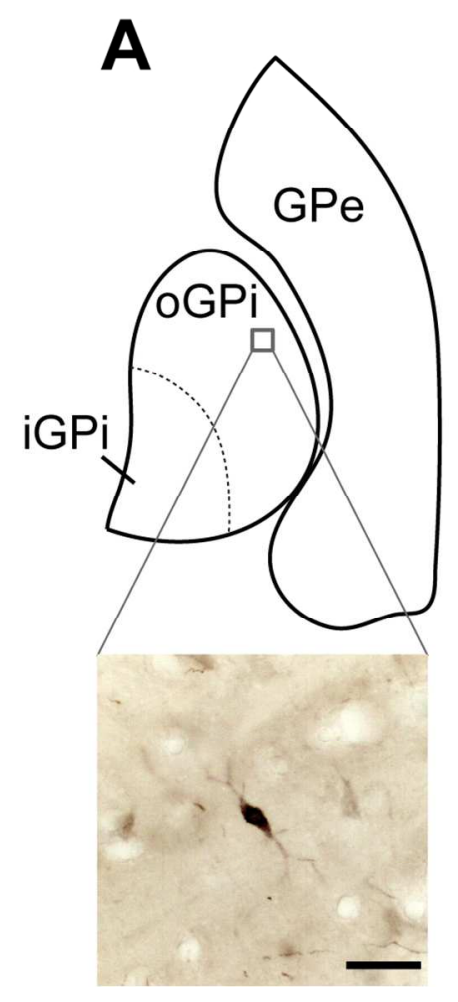

B

C
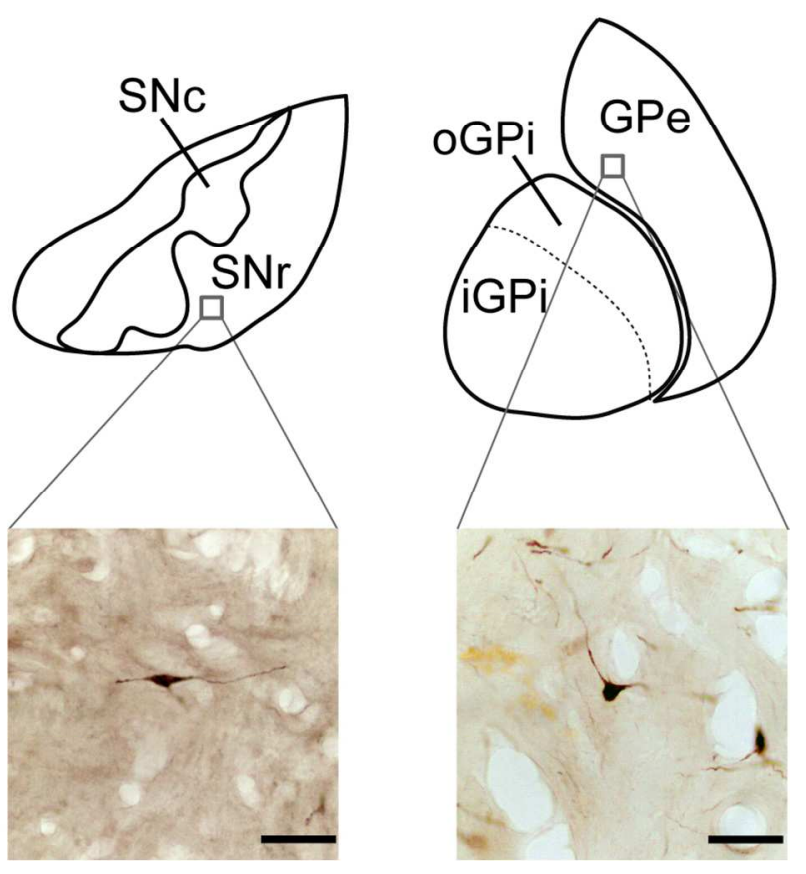

Figure 2

$118 \times 88 \mathrm{~mm}(300 \times 300 \mathrm{DPI})$ 


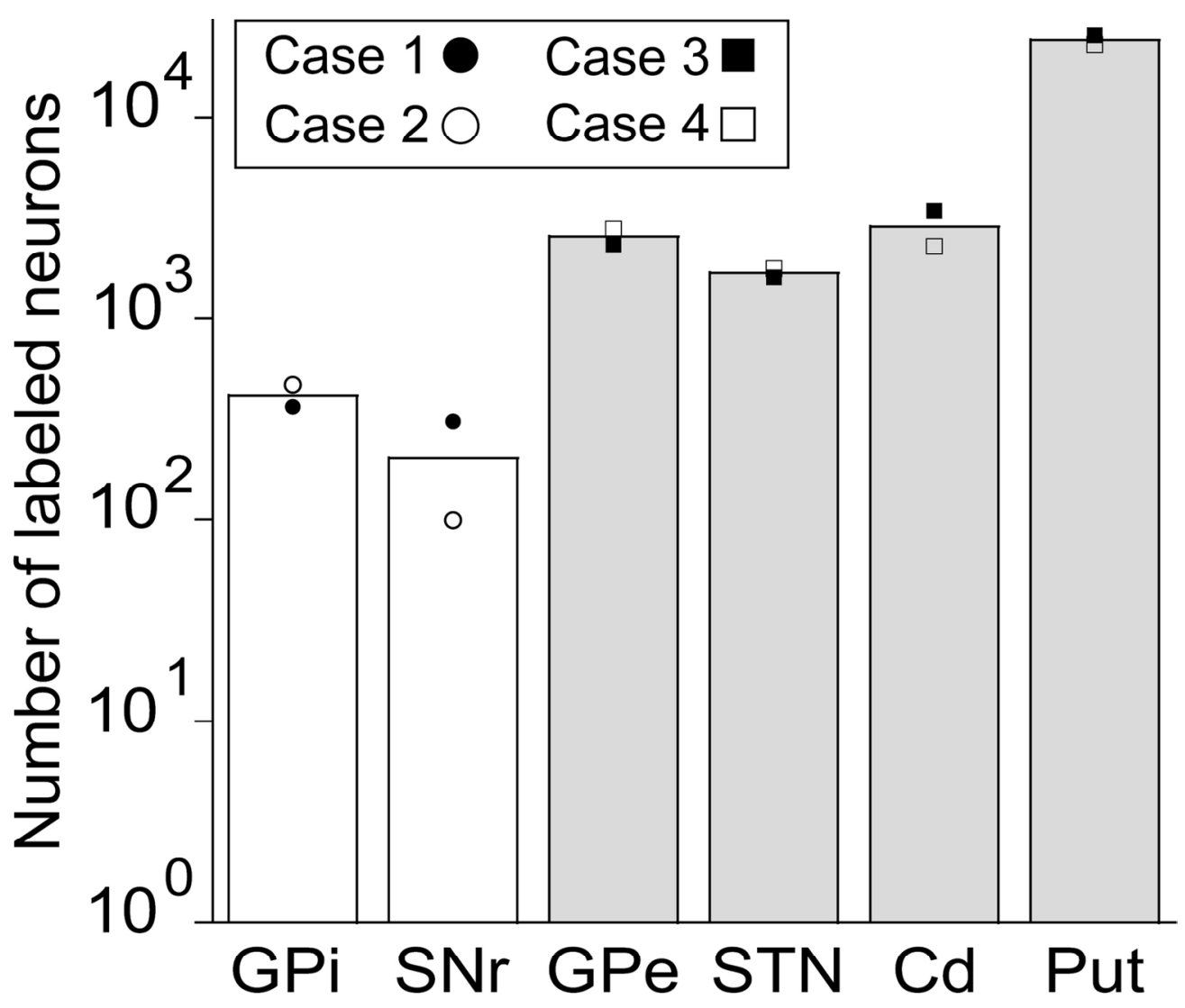

Figure 3

$70 \times 63 \mathrm{~mm}(600 \times 600 \mathrm{DPI})$ 

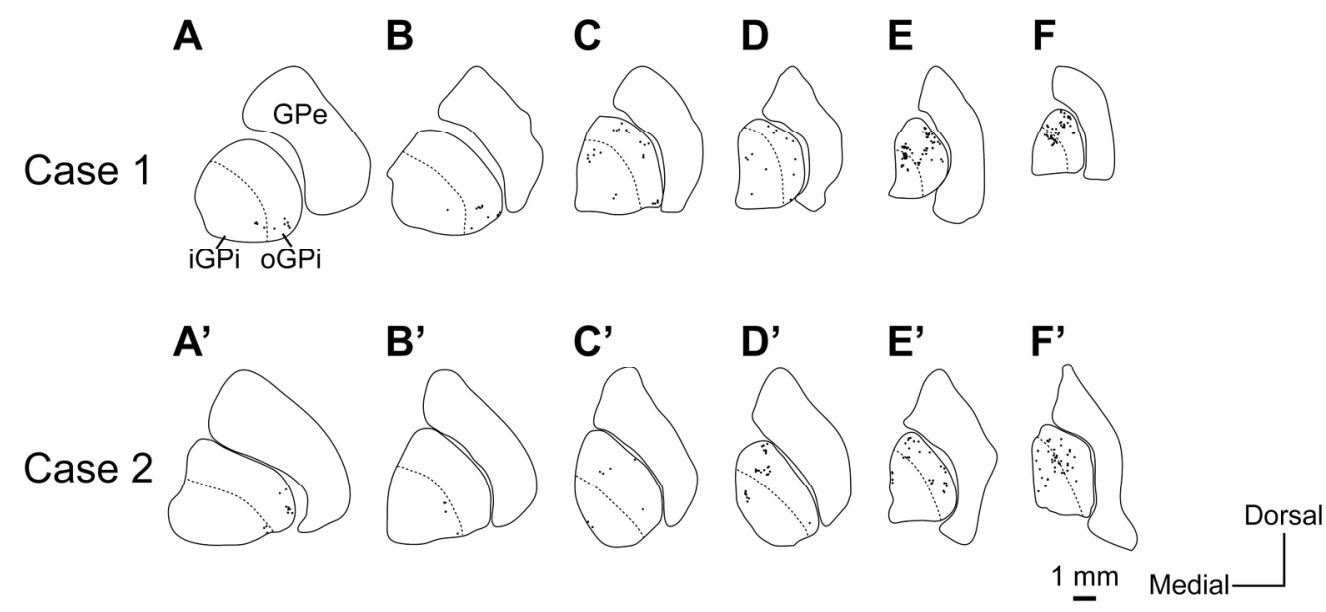

Figure 4

$90 \times 40 \mathrm{~mm}(600 \times 600 \mathrm{DPI})$ 


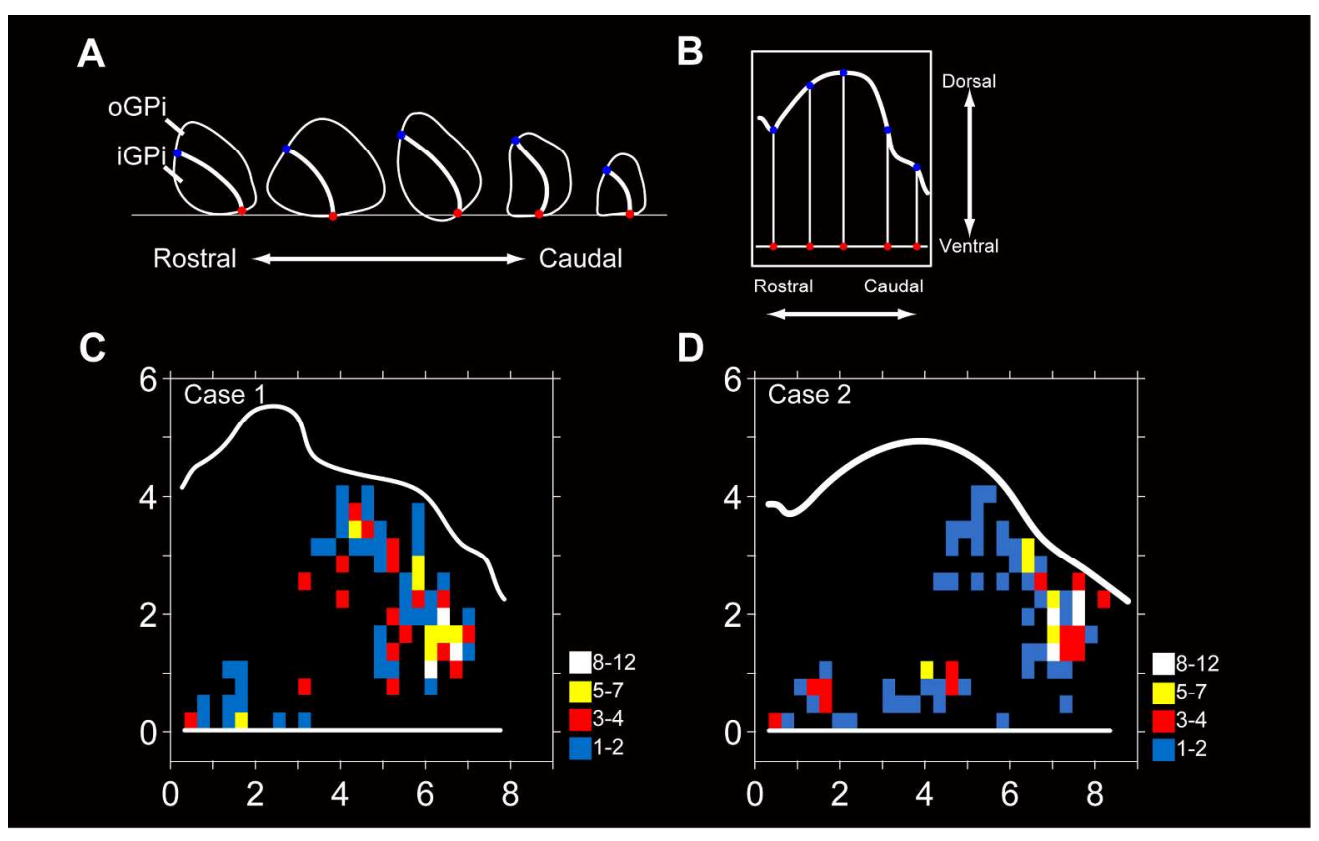

Figure 5

208×129mm (300 x 300 DPI) 


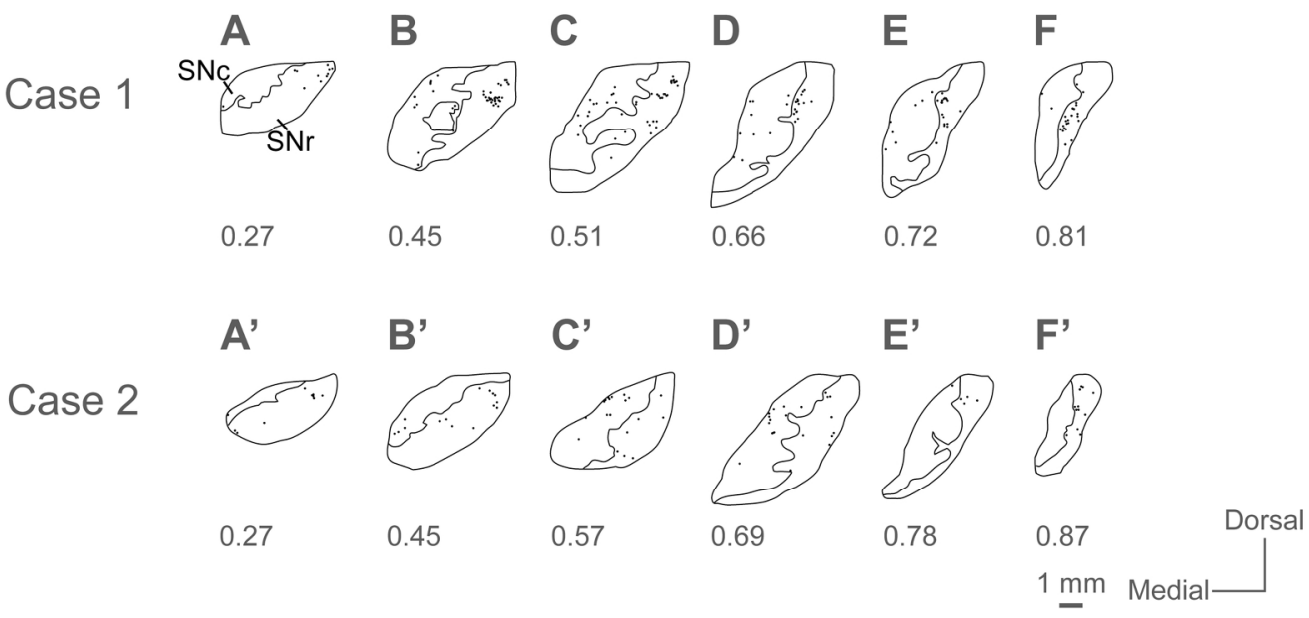

Figure 6 $90 \times 41 \mathrm{~mm}(600 \times 600$ DPI $)$ 
京都大学

European joưfnán of Neuroscience

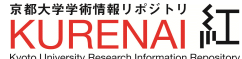
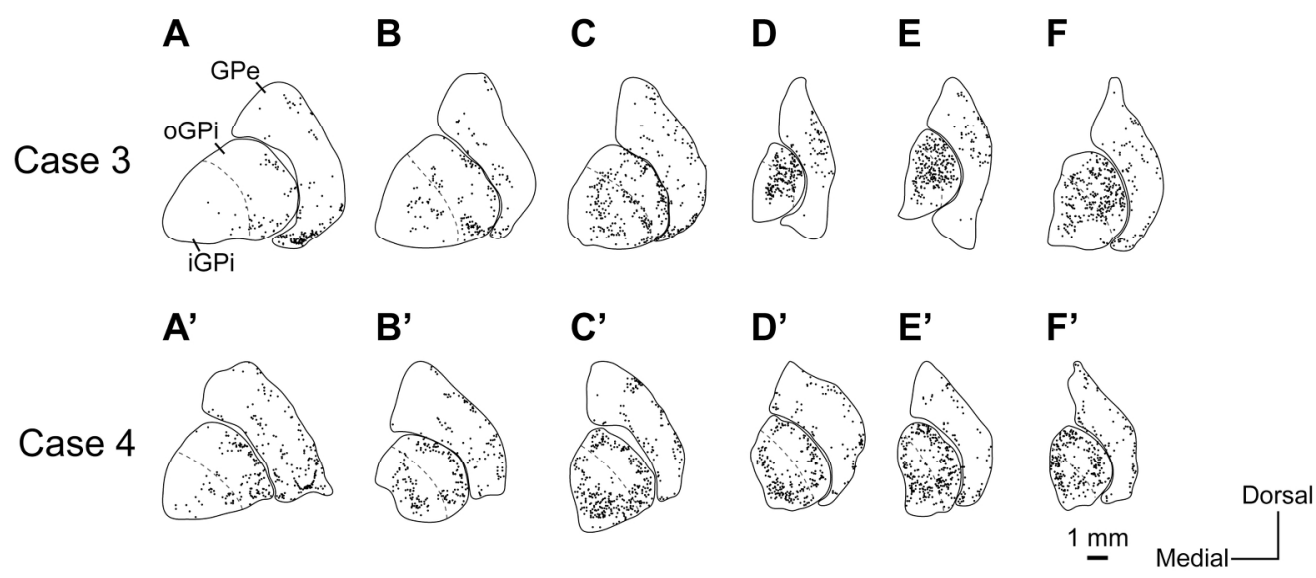

Figure 7

$95 \times 40 \mathrm{~mm}(600 \times 600 \mathrm{DPI})$ 


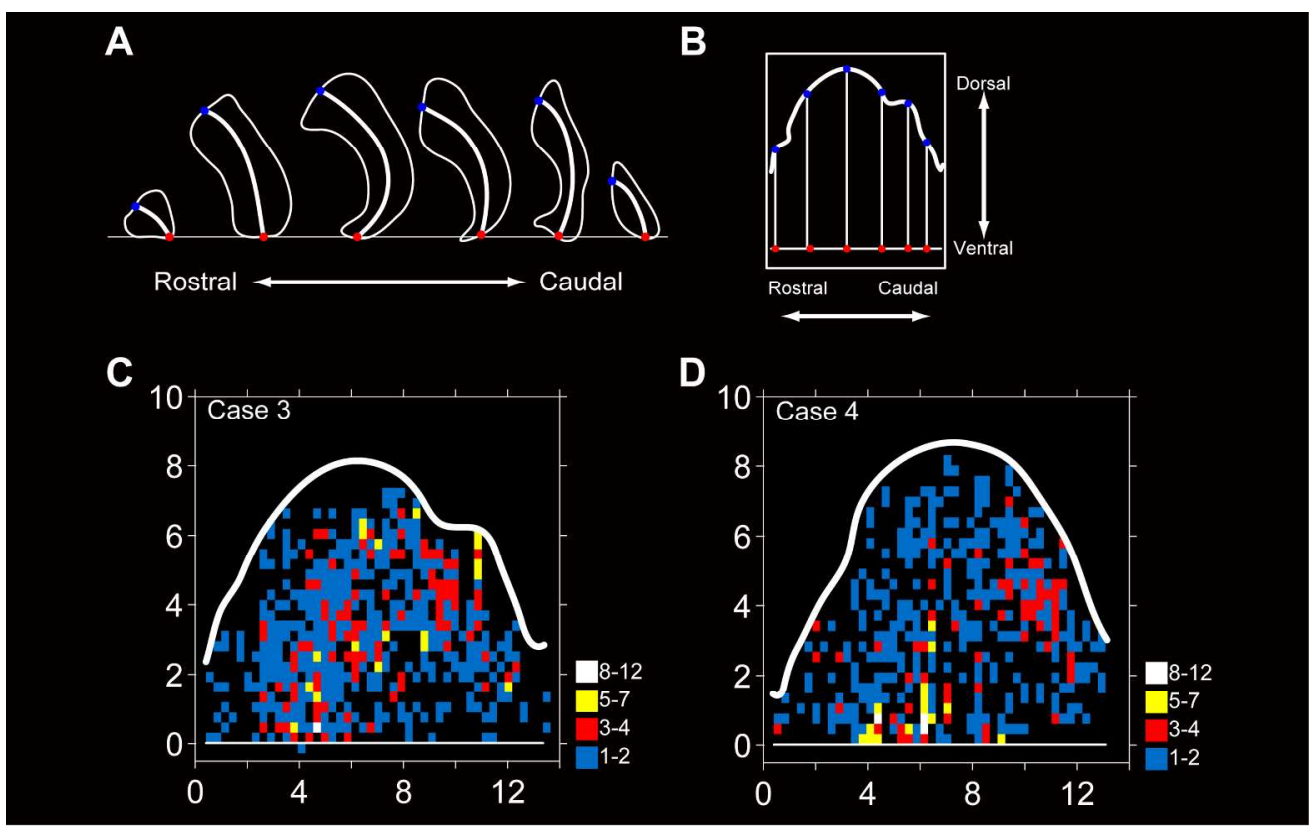

Figure 8

$208 \times 130 \mathrm{~mm}$ (300 x 300 DPI) 


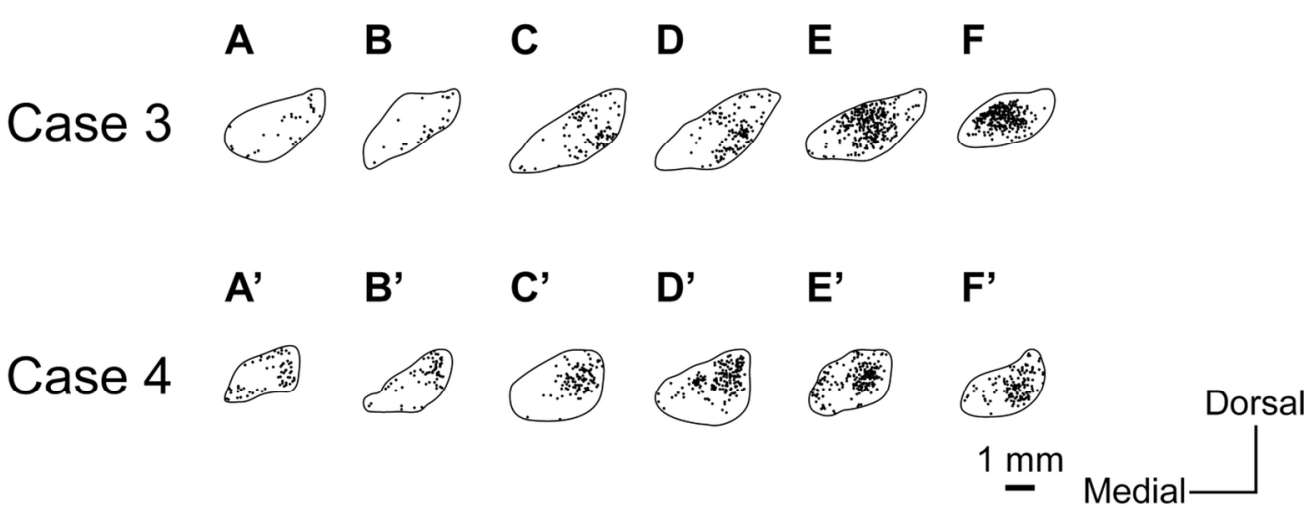

Figure 9

$59 \times 22 \mathrm{~mm}(600 \times 600$ DPI $)$ 

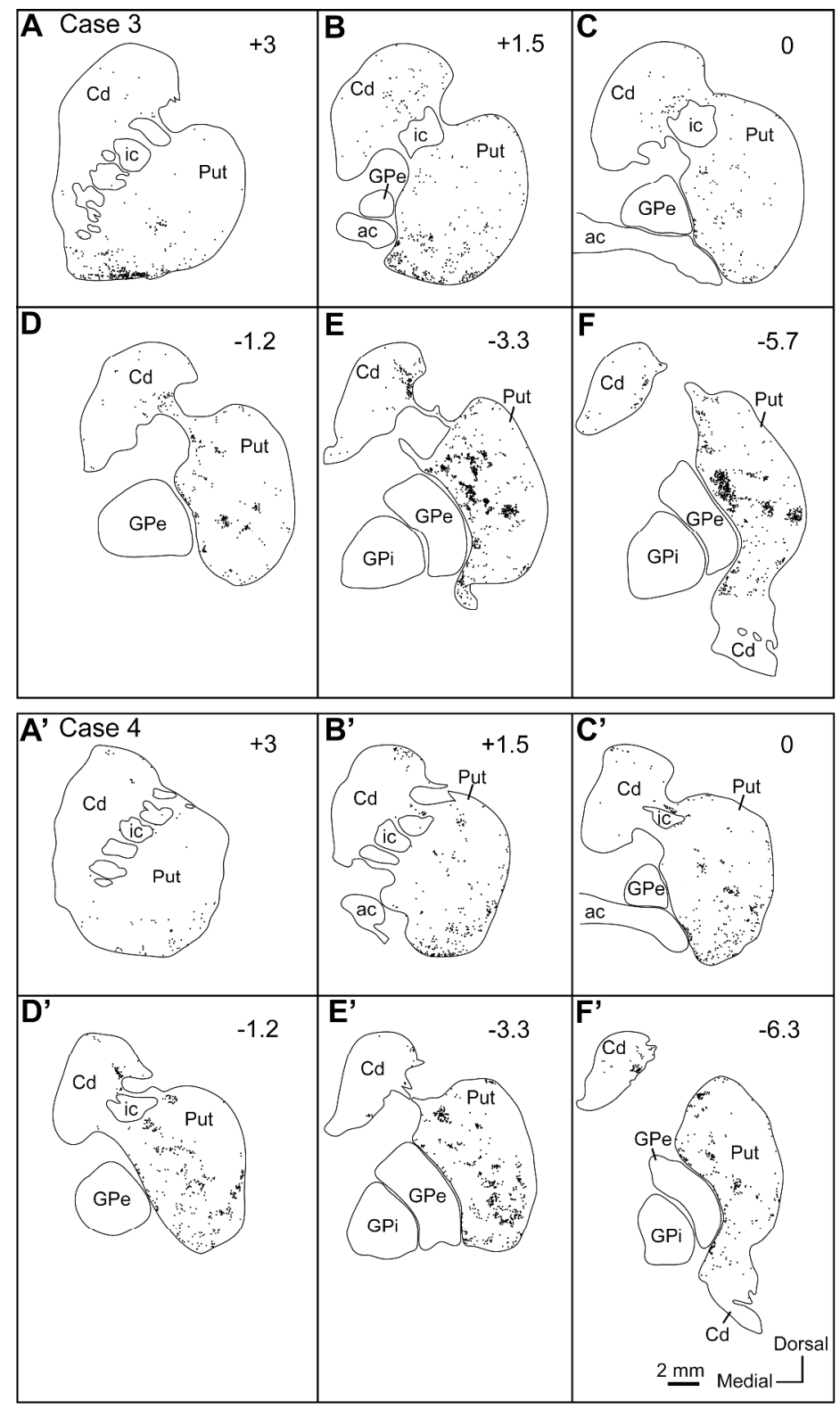

Figure 10

$255 \times 434 \mathrm{~mm}(600 \times 600 \mathrm{DPI})$ 

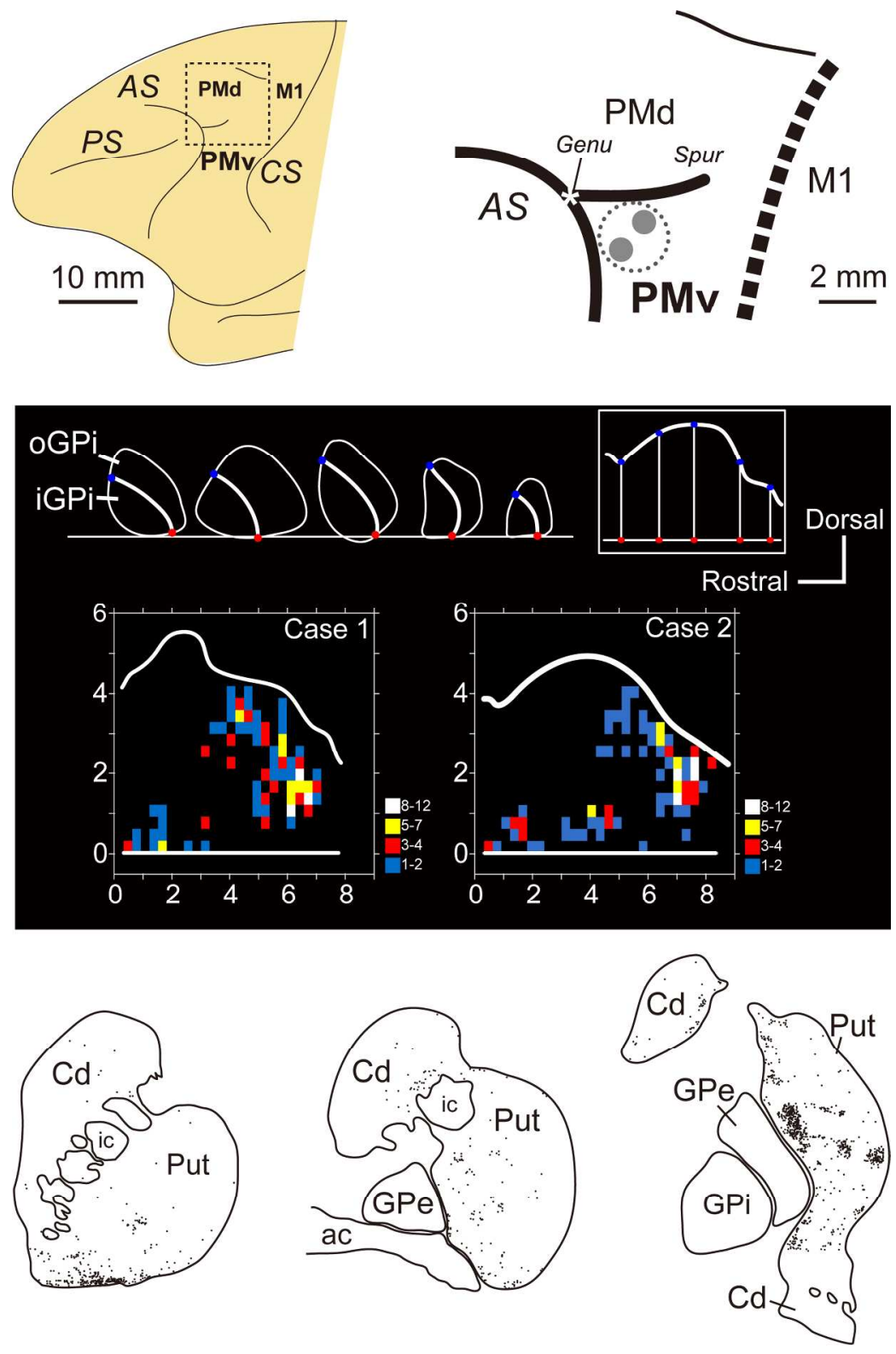

$159 \times 241 \mathrm{~mm}(300 \times 300 \mathrm{DPI})$ 
We employed retrograde transneuronal labeling with rabies virus to identify the origins of multisynaptic projections from the basal ganglia $(\mathrm{BG})$ to the forelimb region of the ventral premotor cortex (PMv) in macaque monkeys. This study revealed that the PMv primarily receives major input signals from multiple territories within each structure of the BG that have comprised the two distinct motor territories (i.e., the primary and higher-order motor territories) and the limbic territory. 